\title{
Potential of Age-management in the Construction Digitalization Process
}

\author{
Jan Lojda ${ }^{1, *}$, Otakar Nemec $^{2}$, Vladimir Nyvlt ${ }^{1}$, and Lenka Lizbetinova ${ }^{1}$ \\ ${ }^{1}$ Institute of Technology and Business in České Budějovice, Okružní 10, České Budějovice, \\ 370 01, Czech Republic \\ ${ }^{2}$ University of Economics, Prague, W. Churchill Sq. 413067 Prague, Czech Republic
}

\begin{abstract}
.
Research background: The article deals with the issue of intergenerational cooperation of different age categories. It follows up on the outputs of the research task "Intergenerational management to support digitization in construction" funded by TACR.

Purpose of the article: The aim of the article is to determine the main problems of intergenerational cooperation and to analyse the current situation from the point of view of solving the necessary changes by introducing digitization in the construction industry.

Methods: When modelling mutual cooperation between generations, it turns out that the key problem is the willingness to cooperate. Interpretation of the results obtained from the research was made through logical deduction and synthesis of previous knowledge in the field.

Findings \& Value added: The findings of the article are in the form of determining the main attributes preventing effective intergenerational cooperation with the aim of sharing digital competencies. The outputs of the article are the cornerstone for the model of intergenerational cooperation based on improving communication between generations, mutual sharing of competencies and thus the use of the strengths of individual cooperating generations (digital competence vs. long-term experience in the field). The research project shows a way to deal with the situation in companies and offers a relatively simple solution that aims to improve intergenerational cooperation and sharing competencies in order to increase the competitiveness of companies. It also offers a way to make effective use of older employees and offer them job satisfaction.
\end{abstract}

Keywords: company management; demographic development; competitiveness; leadership styles; organizational culture.

JEL Classification: $\mathrm{J11}$; M12; O32; O15; M53

\footnotetext{
${ }^{*}$ Corresponding author: lojda@mail.vstecb.cz
} 


\section{Introduction}

Post-industrial society is characterized by a rapid increase in the aging population worldwide, which characterizes one of the most important demographic changes in human history. In the second half of the last century, developed countries in the world have completed a long demographic transition process [1,2]. The demographic transition can be defined as a shift from periods of high mortality, short lives and large families to a smaller family with longer lives and fewer children [3]. This transition has been going on for many years worldwide. This was particularly evident in Europe and North America. Small families changed their way of life and moved from the agrarian countryside to the urban environment with industrial production. Effective health and hygiene measures in public life have reduced the risk of contagious diseases, and modern medicine has extended people's lives to unprecedented length. This demographic transition is under way in developing countries, although there are significant differences between them.

To explore these complex and large-scale demographic changes, scientists use various methodological tools to find, sort and interpret these changes through the "mask" of a "post-industrial society" [3]. A post-industrial society is a society in which there has been a transition from a production-based economy to a servicebased economy, to the use of information communication technologies (industry 4.0). These technological shifts stimulate the restructuring of society as a whole. [4] claims that there have been significant changes in the social fabric associated with the transition to post-industrial society. Although services predominate in a wide range of sectors, health, education, research and government services are critical to a post-industrial society. Already [5] stressed that changes in post-industrial society are not only socio-structural and economic. Values and standards in post-industrial society are also changing. Rationality and efficiency have become the most important values in post-industrial society

Artificial intelligence technologies are cross-cutting in all sectors and their introduction is expected to contribute to increasing productivity and creating new products and services. It is generally believed that the speed of introduction of artificial intelligence into production will bring the greatest benefits [6]. On the other hand, of course, there are questions about the future. The fact that artificial intelligence disrupts current working relationships is more than likely. This does not mean, however, that the total number of jobs must inevitably be reduced, as some jobs will be lost but new jobs will emerge.

The shift of workers from old to new jobs will be related to a change in the technological environment. These changes will depend on the implementation of artificial intelligence. Although artificial intelligence seems to generate concerns about job loss, its impact on the labour market will not be as significant as predicted. The development of technology in the past has always resulted in increased employment and economic wealth of the population. It may happen that there will be a transition period for some time before new working relationships become stable [7]. New technologies [8] always put pressure on higher levels of education and specific skills of employees. While middle-income jobs are likely to be replaced by the introduction of artificial intelligence, competition from manual workers will increase. The pressure on workers at the lowest income level will increase as technological changes will affect their employability more than at higher income categories [9].

This implies that the changes expected with the advent of artificial intelligence will at least in the short-term lead to greater inequality between employees. 
Considerations regarding the impact of artificial intelligence on society and society must also be included in the reflection on the impact of artificial intelligence on production and services [10]. In the future, it will be necessary to create mechanisms for redistributing the wealth of production that, on the one hand, do not restrict the entrepreneurship and development of society, but on the other hand, do not create social tensions in society. The importance of AI is paid extraordinary attention in society, for example, when historically the most money will go to support research and development, next year. Early, intensive and continuous AI attention helps prevent the threat of automation and brings many opportunities. Artificial intelligence is supposed to help people, make their lives easier, so that they gain more time for other creative or caring activities, i.e. activities where emotions are needed that robots don't know and cannot be automated."

Modern information and communication technologies are designed to make life easier for people. "It may be said also about Artificial Intelligence (AI), which belongs to them" [11]. Shifts in all areas occur every day, including AI. Although it is often said that a robot will not build a house, even in construction we are increasingly hearing terms such as digitization, construction 4.0, digital twin, 3D printing or BIM (Building Information Modelling). Certainly one day there will be robotic construction. BIM has been on the agenda of professional conferences and discussions for seven or eight years, but more and more attention has been given to it in recent years. Digitization affects the construction process and its individual phases (spatial, investor and project preparation and implementation), but also links to other areas. This means national infrastructure for spatial information, digitalization of permitting processes or land registry. And these ties will grow in the future. Digitalization is not possible without building information modelling (BIM). One comprehensive digital system then includes all acquired data for current and future use and updates. BIM creates not only a unique database, but is also a prerequisite for easier cooperation between the individual building participants, for the entire building whole-life cycle (from the preparatory phase to the disposal). In addition to BIM is increasingly relies on virtual, respectively augmented reality (such as presentations and virtual tours) or elements of smart homes, offices or industrial premises. Sustainability has also penetrated the construction industry, affecting the choice of materials, structures and technologies. According current research, the main barriers to digital transformation include security, high costs or lack of financial resources and the lack of adequately qualified and trained workforce.

\section{Methods}

The aim of the article is to determine the main problems of intergenerational cooperation and to analyse the current situation from the point of view of solving the necessary changes by introducing digitization in the construction industry. When modelling mutual cooperation between generations, it turns out that the key problem is the willingness to cooperate. Interpretation of the results obtained from the research was made through logical deduction and synthesis of previous knowledge in the field. The research results are based on qualitative data (written notes, conclusions and interviews with participants) of the involved participants (22 pairs) of a construction company in the Czech Republic. Combining key older employees with younger talents, which can be developed, created competency-sharing pairs. The project of sharing competencies took place during 2019, while the year 2018 
provided space for preparation - selection of pairs, explanation of the goal and the way of participation in the project to the participants. The sharing took place in pairs during the meetings according to a pre-agreed schedule. The main goal of the sharing pilot project was to transfer knowledge and experience to the younger generation and to increase the awareness, motivation and IT competencies of the older generation. The obtained qualitative data from written notes, final reports and interim interviews were processed using thought mental maps and summarized according to key features.

\section{Results}

\subsection{The application of solution inter-generational cooperation in a construction enterprise}

The project of the Technological agency of the Czech Republic addressed the issue of increasing the competence of workers based on their mutual cooperation and sharing in the intergenerational context. The construction sector was chosen for two basic reasons:

- There is a long-term lack of quality human resources in the construction sector.

- This is an area that, like others, is undergoing turbulent changes due to the arrival of the 4th Industrial Revolution.

Thus, construction companies face two challenging human resource challenges. Not only is there a lack of quality human resources, but also at the same time their structure of necessary competences is gradually changing with the advent of digitization. This situation is not easy for companies, but it can be solved. Bringing together the competences of the younger generation, which has the capacity and flexibility of digital technology, and the older generation, which is experienced, has a wealth of expertise and perspective in accessing projects, can greatly help companies overcome this problem. The best way to implement this idea was to identify and create pairs that could identify and share their unique competencies. The application guarantee (construction company) was chosen within the project, which coincided with the implementation within the pilot project. As part of the pilot project, 22 couples were selected and selected to participate in individual competency sharing processes. The main focus was on sharing in the context of digitization. The platform for sharing notes and reports of couples was the software that the company plans to use for the transmission and storage of digitized documents has been selected as the It environment for the pilot project. This will familiarize workers with this software environment.

As with other change-generating projects, in the pilot project of intergenerational competence sharing, the success of the project depended on the initial communication, the explanation of its benefits and needs, as well as the motivation of the staff for the idea. Given the importance of this initial phase, a motivational meeting with all participants and management took place.

This was followed by the work of couples during which they were supported by mentors and IT staff to work in the IT environment. All participants have created their competencies within the e-portfolio. Using open questions, participants had the opportunity to identify competencies that they had not previously realized but used them. They then identified areas that are needed for performance within the enterprise and that they can share with a colleague. There were several meetings within the pairs, where they shared their e-portfolios and discussed the possibilities 
of mutual sharing and the need to develop competencies. Based on the final reports, the bottlenecks and the most valuable benefits of the pilot process were summarized:

- As anticipated, the most risky parts of the implementation were the need for internal set-up to share competencies - that is, understanding this need, its benefits for both the individual and the counterparty. Employees who were sufficiently motivated to share identified the perceived educational needs, willingness to cooperate, and thus an understanding of the needs and potential of the counterparty. This closer understanding has strengthened relationships, improved communication, and the process of sharing competences has begun. The process with the resulting synergistic effect was performed in $25 \%$ of the couples.

- Supervision and support of the superiors has also proved to be very important in the process. It has become evident that the selected managers who are able to motivate their subordinates correctly and at the same time provide support within the process of sharing and cooperation, the results of the work of the couples brought visibly better conclusions.

- Support, communication and mentor attitudes were also one of the attributes that proved to have a significant impact on the intergenerational sharing process. Participants often approached the mentor when creating an e-portfolio, when they needed guidance in the process of correctly identifying their hidden competencies. Since the process could be improved by including an exercise for this identification at the initial motivation meeting, or by including a workshop for participants to create e-portfolio and work in the IT environment.

- A joint meeting at the end of the pilot project where the results have been summarized seems to be an appropriate form to encourage further motivation to maintain the process of sharing in society and its integration into organizational culture.

The pilot project demonstrated the suitability of applying intergenerational sharing to the needs of construction companies during the transition to digitization as one of the effective options for increasing the necessary skills of workers. Its implementation within the pilot project brought about the recognition of their own educational needs and motivation for workers, as well as deepening the existing cooperation and enriching it with the process of mutual learning with each other. Expanding the scope of implementation in the enterprise and a longer-term application could bring a change in approach and awareness of this process and its understanding as part of the element of corporate culture.

\subsection{Results of inter-generational management research in the Czech Republic}

Introducing and implementing Intergeneration Portfolio Management is a learning experience in itself. Several barriers had to be conquered. The organisation had to adapt its principles. People had be motivated by Human Resource Manager and their In-line Managers to bridge generation gaps. Coordinators and unit managers were convinced at the special seminar to support this process. The outcomes were not possible to foresee. The whole process was based on assumption, that the organisation willing to learn. It was important to get a feedback of the work of pair of co-workers linking her career plan with the future. It was helpful to express all 
the competences and to get a feeling about them standing in the organisation. Positive feedback encouraged the workers and reinforced the way she approaches their work, negative feedback helped to change and improve the individual's style of working. Team leaders and managers were involved in the mutual learning process and they monitored the conversation between young and older workers. They supported and stimulated the intergenerational collaboration in the team. They were interested in the outcomes of the discussions and in the individual portfolios. The eportfolio was used as a guidance in their annual personal career review. It helped to identify new learner needs. Working with competences and portfolios made behaviour of workers more measurable. The implementation might take time, but the results in the long term brought to workers many benefits. The personal portfolios have proven to be an evolving document and as such needs to be regularly reviewed and updated. It has been found that personal portfolios are helpful in sharing work experience and are evidence of the continued personal development of employees.

\section{Discussion}

\subsection{What are the differences in the attitudes of different generations to the need for education and employment?}

Nowadays, it is undisputed that the main influence on the performance of employees and the competitiveness of companies belongs to information technologies. Information technology determines the relationship to work across age groups of employees, thus blurring the differences between generations. Few older workers today see information technology as an obstacle to their profession. This attitude is more prevalent in Europe than in Asia. But even in Europe, the ability to work in an IT environment with a high degree of information digitization by companies is required. All generations of workers, without exception, realize that adapting to the current trends of digitization will ensure them a better position in the labour market and will ensure their continuing working life for the next ten years. Great hopes are put into training and job training. Although the interest in in-service training is gradually declining with age, it still accounts for more than two-thirds of the " $\mathrm{X}$ " generation of employees who are in need of further in-company training. Regardless of age, however, at least one quarter of the staff still prefer personal contact with the teacher over online courses [12].

There is also a growing concern among older workers whether they will be able to join multi-generation teams in the coming years and consider it a job loss. They do not consider it beneficial to enjoy retirement. The inability to enjoy retirement increases with education and employers should carefully perceive these older workers' preferences and try to use them to their advantage. Thus, preferences vary between generations, but interest in employment, new technologies, continuing education and corporate culture is characteristic across generations [13,14]. It follows that the generation differences are not as great as they are perceived. Especially our thinking, which influences the relationship to work and further education, has a great influence on our behaviour. The corporate culture can also play a significant role here, as it can motivate employees to stay in working teams until they are older [15]. 


\subsection{Accepting generational differences}

The new emotions of the millennials are the greatest emotions in the joint workplaces. This future employer base raises some concerns for employers. Apart from the declarative statement that this generation is a challenge for existing company management, it is important to realize that companies will not be able to make real benefit from it. For young employees, the sense of commitment to the organization $=$ employer and interest in corporate culture decreases. The original relationships at the workplace are subject to a severe test because the original value links between duty, work and subsequent pay are severed. The motivation of younger workers needs to be much more focused on their satisfaction and selffulfilment. The popular formulation of younger employees to crave work to meet them meets the needs of an employer who requires performance. Employers must note that the young generation thinks differently about their working life. Understanding their approach can mean not a challenge for companies, but a change in motivation techniques and management practices. Performance evaluation must be preceded by a more detailed examination of the attitudes of the young employee. An entirely different range of measures will have to be taken in human resource management to take advantage of the employment of the youngest generation [16].

\subsection{Impact of generations clash on company management}

Difficult task is to specify the impact of a conflict of generations on company management. This is because the success of an organization depends on a number of factors whose importance changes over time. The decisive factor is effective targetoriented leadership. Leadership styles vary from generation to generation, and in general, the oldest generation highlights honesty, disillusion, mutual respect among employees, and responsibility as core values of the company. For young employees, the need for leadership decreases and the importance of independence in the performance of tasks increases. Mutual intergenerational communication is increasingly important for the success of the organization. The impact of a particular management style on the competitiveness of a company depends on the structure of its employees and the strength of the corporate culture. The leadership style of multi-generation teams must focus on communication gaps and actively promote intergenerational communication. In addition to communication, it is also necessary to promote mutual learning, which can reduce the costs of education and training while increasing the coherence of the work teams [17].

Transformation management style focuses on the ability of managers to motivate their subordinates through visions, goals and actions. In addition to these three pillars, the focus is on creativity as part of worker stimulation. The disadvantage of this approach is the subjective individual consideration of the managers. In contrast, participatory science [18] focuses more on consensus negotiation of organizational goals. However, consensus negotiation can lead to conflicting results. Participative leadership should lead to the right decisions, clear responsibilities for the tasks entrusted and the implementation of tasks by the responsible persons. The benefits of participatory leadership are greater job satisfaction, increased individual motivation, and easier conflict resolution. Participative leadership in no way restricts authoritative leadership if the collective agrees. Creating a harmonious working environment is seen as the most important element of intergenerational cooperation. This requires a good respect among employees and a joint effort to achieve corporate goals. However, Jurkiewicz [19] and Bartley [20] dispute the 
general validity of those assumptions. He admits that generations are different and the differences between them are well described, but more of a burden on sharing values and leadership style. Work ethics based on democratic and humane approaches have resulted in participatory management, which is characterized by consensus, teamwork and the involvement of quality workers [21]. Conflicts with those who profess other values and are unwilling to submit to authority and intimidation should be avoided. These people do not feel dependent on work and need to be motivated by other means. Informal work environments and flexible working hours can be a good help in getting involved in teamwork.

Previously used direct management combined with the effort to keep everything under control perfectly and does not sufficiently reflect the equality of co-workers and does not realize sufficiently the benefits of teamwork. It is not enough to be convinced of the benefits of participatory leadership, but needs to be implemented in the workplace. Participative leadership requires managers to listen, communicate, motivate and, above all, know delegation techniques. Delegation brings to working teams the necessary enhancement of competencies of all team members. It responds well to the working preferences of younger workers and brings harmonizing effects to the cooperation. However, it is necessary to suppress the personality of the managerial style of each manager, who prefers the trans-form style of management.

\section{Conclusion}

The aim of the article is to determine the main problems of intergenerational cooperation and to analyse the current situation from the point of view of solving the necessary changes by introducing digitization in the construction industry. The findings of the article are in the form of determining the main attributes preventing effective intergenerational cooperation with the aim of sharing digital competencies. The outputs of the article are the cornerstone for the model of intergenerational cooperation based on improving communication between generations, mutual sharing of competencies and thus the use of the strengths of individual cooperating generations (digital competence vs. long-term experience in the field). The research project shows a way to deal with the situation in companies and offers a relatively simple solution that aims to improve intergenerational cooperation and sharing competencies in order to increase the competitiveness of companies. It also offers a way to make effective use of older employees and offer them job satisfaction.

Based on research conducted in a particular company, it has emerged that intergenerational issues and cooperation require support. The research focused on the workers themselves and on the management of the company. The project outputs show that the differences of generations are reflected in the work of the company and each age generation requires a different style of leadership. The research results do not depart from the framework that can be found in the literature. At present, the leaders of companies are mostly members of the " $\mathrm{X}$ " generation. This does not mean that there will be no shift in leadership towards younger generations in the short term. Given the generalization that the " $X$ " generation prefers situational management, we find that although this generation is very important for the competitiveness of companies, it is necessary to focus on all generations present in the company. The style of management requires adapting to subordinates and here to other generation. Generational differences must be seen as a challenge. Generational differences can have a significant impact on the company's success. Greater willingness to cooperate and share competencies has a positive impact on 
the organization's performance. Intergenerational sharing, which was at the heart of the research, has shown that it leads to increased productivity, better relationships in the workplace, and easier retention of employability of employees at older age. Conversely, established stereotypes in the perception of generations and a low level of intergenerational understanding inevitably lead to clashes and increase employee turnover and reduce labour productivity. In the literature, we find a fan of strategies rather than concrete advice on how to proceed in the event of an intergenerational conflict. Research on the potential for intergenerational sharing has clearly demonstrated that good results can only be achieved with sufficient attention from management. The company culture and support of intergenerational communication play an important role in coping with the intergenerational clash. The tested method of intergenerational cooperation based on the cooperation of couples and their mutual sharing of competences and values showed that it brings results. The sustainability of these results then depends on the management of the company, how it can implement them in the culture of the company and further deepen them.

The article is elaborated as one of the outputs of the research project which has been financed by TAČR (ÉTA) - project TL02000017 Inter-generation Management for the Support of Digitalization in the Building Industry.

\section{References}

1. Higo, M., Khan, H. T. A. (2014). Global Population Aging: Unequal Distribution of Risks in Later Life between Developed and Developing Countries. Global Social Policy, 15(2), 146-166.

2. Khan, H.T.A. (2013). Factors Associated with Intergenerational Social Support across the World. Ageing International, 39, 289 - 326.

3. Hendricks J., Powell, J.L. (2009) The Welfare State in Post-industrial Society: The Lay of the Land. New York: Springer, New York.

4. Ritzer, G. (2007). The Globalization of Nothing. CA: Pine Forge Press.

5. Trosow, S.E. (2000). The coming of post-industrial society: A venture in social forecasting. Library Quarterly, 70(3), 397-399.

6. Mura, L., Gontkovicova, B., Dulova Spisakova, E., Hajduova, Z. (2019). Position of Employee Benefits in Remuneration Structure. Transformations in Business \& Economics, 18, (2(47)), 156-173

7. Meszaros, M., Divekyova, K. (2019). Immediate termination of employment relationship by the employer. Central European Journal of Labour Law and Personnel Management, 2(2), 33-43.

8. Sal, J., Dedic, M (2020). Application of Modelling Processes and 3D Print on Casting Moulds for Concrete Furniture. IOP Conference Series: Materials Science and Engineering, 728, Article Number 012014.

9. Rozsa, Z., Kmecova, I. (2020). Cyber vetting prospective employees of SMEs. Journal of International Studies, 13(1), 295-309.

10. Bilan, Y., Mishchuk, H., Roshchyk, I., Kmecova, I. (2020). An Analysis of Intellecutal Potential and its Impact on the Social and Economic Development of European Countries. Journal of Competitiveness, 12(1), 22-38. 
11. Vinuesa, R., Azizpour, H., Leite, I., et al. (2020). The role of artificial intelligence in achieving the Sustainable Development Goals. Nature Communications, 11, Article Number 233.

12. King, E., Finkelstein, L., Thomas, C., Corrington, A. (2019). Generational Differences At Work Are Small. Thinking They're Big Affects Our Behaviour. Retrieved from: https://hbr.org/2019/08/generational-differences-at-work-aresmall-thinking-theyre-big-affects-our-behavior

13. Belas, J., Kmecova, I., Cepel, M. (2020). Availability of human capital and the development of the public infrastructure in the context of business activities of SMEs. Administratie si Management Public, 34, 27-44.

14. Lorincova, S, Hitka, M., Balazova, Z. (2016). Corporate Culture in Slovak Enterprises as a Factor of HRM Quality - Case Study. International Journal For Quality Research, 10(4), 719-732.

15. Hitka, M., Kozubikova, L., Potkany, M. (2018). Education and Gender-Based Differences in Employee Motivation. Journal of Business Economics and Management, 19 (1), 80-95.

16. Stewart J. S., Goad Oliver, E., Cravens, K. S., Oishi, S. (2017). Managing millennials: Embracing generational differences. Business Horizons, 60(1), 4554.

17. Salahuddin, M. M. (2011). Generational Differences Impact On Leadership Style And Organizational Success. Journal of Diversity Management, 5(2), 1-6.

18. Horsfall, C. (ed.) (2001). Leadership Issues: Raising Achievement. London: Learning and Skills Development Agency.

19. Jurkiewicz, C.L. (2000). Generation $X$ and the public employee. Public Personnel Management, 29(1), 55 - 74.

20. Bartley, S.J., Ladd, P.G., Morris, M.L. (2007). Managing the multigenerational workplace: answers for managers and trainers. CUPA-HR Journal, 58 (1), 28-34.

21. Bencsik, A., Juhasz, T., Mura, L., Csanadi, A. (2019). Impact of Informal Knowledge Sharing for Organizational Operation. Entrepreneurial Business and Economics Review, 7(3), 25-42. 